\title{
Tiburzio Spannocchi, ingeniero mayor de los reinos de España
}

\author{
Alicia Cámara Muñoz
}

Desde que en 1574 se hizo constar la alarmante falta de ingenieros competentes en la península, los virreyes de Nápoles y Sicilia, y el gobernador de Milán fueron encargados de buscar y enviar a España a los mejores que encontraran en sus respectivos territorios. Entre los que fueron enviados se encontraba Tiburzio Spannocchi; fue el virrey de Sicilia quien lo envió en 1580 y, una vez examinado por Francisco de lbarra el 15 de febrero de ese año, fue encontrado muy hábil en lo que a "designios" se referia, pero con poca práctica y ninguna experiencia en el campo de batalla'.

Era noble de nacimiento -el árbol genealógico de los Spannocchi de Siena se remontaba hasta Ambrogio di Ser Mino da Spannocchia, en 1359- y el argumento de su nobleza era uno de los méritos que en su persona señalaba el virrey, además, por supuesto, de traer de Sicilia una bien ganada fama como ingeniero. Sicilia era el uprimer baluarte de Euro$\mathrm{pa}$, frontera del Africa y del Asia, y plaça de armas de las fuerças maritimas y catolicas" ${ }^{2}$, y Spannocchi trajo consigo trazas de las fortificaciones de ese baluarte del Mediterráneo que era la isla de Sicilia.

En la Biblioteca Nacional de Madrid se conserva un manuscrito de Spannocchi en el que se describen las marinas del reino de Sicilia y en él afirma este ingeniero haber servido al rey de España durante tres años en esa isla. La descripción fue escrita en 1578, el mismo año en que el virrey Marco Antonio Colonna «rescibio carta de su Magd. en el que le ordenava

Colección Aparici, Tomo VI, pág. 4.

2 Muerte del príncipe Emanuel Filiberto de Saboya, Virrey de Sicilia y Principe de la Mar. Relación de su entierro y honras (1624). B.N.M., Ms. $n^{\circ} 2355$, f. 67. 
le enbiase alguna persona avil en cosas de fortificacion" ${ }^{3}$, de resultas de lo cual fue él el enviado. Afirma en esta obra estar haciendo una descripción similar de los reinos de España (el manuscrito está fechado en 1596), que por supuesto no está destinada a ser impresa, y en la que refleja todos los conocimientos adquiridos sobre la península en sus múltiples viajes como ingeniero ${ }^{4}$.

El manuscrito sobre Sicilia nos aproxima a la diversidad de intereses y de cometidos de un ingeniero, pues da cuenta de la riqueza de Sicilia con todo detalle (los efectos benéficos del Etna, su vino, su aceite, queso, pescado, ingenios de azúcar, seda, miel, sal, madera...), de la defensa de la isla y cómo mejorarla, del precio de las fábricas y de sus medidas, del valor de las monedas del reino, de las medidas de longitud tanto en Italia como en España (esto en un papel suelto), del número de vecinos, millas, guardias, castillos, torres, y gastos en todas las marinas de Sicilia, incluyendo además perfectos mapas a escala.

Muestra su sensibilidad ante la belleza artística en algunos párrafos, $y$ afirma haber sido él mismo quien sacó y levantó los cimientos de la Casa Real de Palermo ${ }^{5}$. Desde el punto de vista del urbanismo -además de importantes vistas de otras ciudades- de noticia y reproduce la planta de la ciudad de Carlentini ${ }^{6}$, entre Catania y Augusta, un poco hacia el interior

\footnotetext{
${ }^{3}$ Descripción de las marinas de todo el Reino de Sicilia. Con otras importantes declaraciones notadas por el Cavallero Tiburcio Spanoqui del Abito de San Juan Gentilhombre de la Casa de su Magestad. Dirigido al Principe don Filipo nuestro señor en el año de MDXCVI. B.N.M., Ms. $n^{\circ} 788$. Es un manuscrito con dos tipos de letra: una para la redacción en castellano y otra para lo italiano, que se alternan hasta el folio 55 . Desde el folio 56 al 91 el texto es sólo italiano. Está ilustrado con bellos dibujos en dos formatos: $10,5 \times 32,5 \mathrm{~cm}$ y $4,5 \times 3,5 \mathrm{~cm}$. Estos últimos a veces se alargan cuando además de la torre fortificada incluyen la planta del edificio, y se encuentran en los márgenes del texto.

${ }^{4}$ L.A. MAGgIOROTII.: L'Opera del genio italiano all'estero, Gli architetti militari. Vol. III: Gli architetti militari italiani nella Spagna, nel Portogallo e nelle loro colonie. Roma, 1939, pág. 168.

5 «... parecio bien al Virrey y consejo mandar hazer una casa Real en la Ciudad de Palermo como caveça de todo el reino y donde de ordinario suele residir la Corte en la qual casa se pudiesen juntar ministros assi de lo civil como de lo criminal y el Real patrimonio con los archivos para conservación de escrituras públicas de todo el Reino y sobre el lugar eligido para ello fue menester hazer planta y por mi orden se sacaron y levantaron los cimientos". Las palabras "por mi orden" tienen un papel pegado encima. Descripción..., op. cit., f. $5^{\text {vo }}$.

${ }^{6}$ Esta ciudad de Carlentini se hizo porque cerca de Lentini había dos estanques que corrompian el aire, pero muy pocos de los vecinos de Lentini dejaron su ciudad para trasladarse a la nueva. Las razones que llevaron a decidir la ubicación de la nueva ciudad en tiempos del emperador Carlos fueron las siguientes: "en una montaña media milla de alli muy apropiada assi por el temple del aire como por la fortaleça y capaçidad pues tiene en la cumbre un anchuroso llano en el qual a dos canas (sic) del suelo se allan perfectisimas aguas demas de una abundante fuente a que alli ay agua de pie". Sin embargo, los planes fallaron, pues pocos fueron los que se animaron a habitarla: “Començose desde entonçes la
} 
de la costa, iniciada en tiempos del emperador Carlos V, del cual toma su nombre (Lentini es una ciudad cercana a ésta). Esta ciudad, trazada en damero, es un eslabón más en esa cadena de ciudades en territorios colonizados, que culminará con la reticula ortogonal de las ciudades americanas.

Nada más llegar a la península fue encargado Spanoqui (asi firma muchas veces, y asi lo llamaremos desde ahora, aunque será llamado en los papeles Espanoqui, Espanochio, Espanochi, Fra Tiburcio, Tribulcio Hispanochi, Hispanoqui, etc.) de las fortificaciones de Fuenterrabía. Poco después, en 1581, dio traza para los fuertes del Estrecho de Magallanes, y su instrucción sobre el modo de construirlos ya la publicó Llaguno?, aunque nunca llegaran a construirse. En 1583, y quizá teniendo en cuenta la necesidad de esa "experiencia" que se habia echado en falta en su formación, participó en la expedición a las Islas Azores. Mosquera de Figueroa relata parte de lo que fueron sus funciones en la expedición: "Tiburcio Espanoque, cavallero del habito de $\mathrm{S}$. Juan, exercitado en las Mathematicas, mostro con estendido discurso y mucha advertencia y puntualidad la descripción desta Isla (Tercera) assi en lo que toca a la Cosmografia, como a la Geografia, con toda particularidad de lugares..." ${ }^{8}$. Resultado de esta experiencia fue el proyecto de fortificación que hizo en 1584 para esa isla.

Dio con frecuencia su parecer sobre las fortificaciones americanas; en 1588 aprobó el plan de fortificaciones propuesto por Antonelli para el Caribe. Se ocupó también de la fortaleza del Morro en La Habana y ese fue uno de los casos -otro fue por ejemplo el de los fuertes de Cartagena

\footnotetext{
cerrca desta nueba Ciudad y hasta oy dia no se a acabado de cerrar. Para animar la gente al proseguimiento de la nueva población concedio grandes previlegios y esenciones a los que biviesen y fabricasen alli casas, an concurrido de diversas partes del Reino algunas personas pobres y empeñadas para goçar de dichas franqueças de manera que avra de presente como trecientos y sesenta vecinos, y dellos muy pocos de la Ciudad de Lentini". Idem, t. $31^{\mathrm{v}}$. Sobre Carlentini y, en general, sobre las fortificaciones de Sicilia se puede ver también las Advertencias que el Duque de Medinaceli dejó a D. Garcia de Toledo sobre el gobierno del reino de Sicilia. De Mesina a 3 de enero de 1565. En Colección de Documentos Inéditos para la la Historia de España, tomo XXVIII, Madrid, 1856. De Carlentini dice que uestá doce millas del puerto de Augusta y veinte y cuatro de Zaragoza; y por las mismas calidades que he dicho de Noto, las cuales concurren en él y algunas mayores, el señor Juan de Vega emprendió fortificarlo, $y$ asi lo puso muy delante, y yo lo he continuado y se ha hecho razonable parte, pero no tanta cuanta yo quisiera. $V . S^{a}$. debe a mi parescer procurar de que se acabe la fabrica, porque, como verá, será una gran seguridad para este reino".

7 E. Llaguno,: Noticias de los arquitectos y arquitectura de España. Ed. de 1977, tomo III, pág. 85 y 266 y ss.

${ }^{8}$ C. MOsouera DE Figueroa: Comentario en breve compendio de disciplina militar, en que se escrive la jornada de las islas de los Açores. En Madrid, por Luis Sánchez: Año 1596. f. $70^{\text {vo }}$ y 71 .
} 
de Indias- en que entró en conflicto con los ingenieros que trabajaban en América, pues sólo ellos conocian aquellas tierras y lo que alli era necesario. En ese sentido escribía Antonelli por ejemplo sobre el Morro en 1596, que «no convenía hacer arcos como los de Cádiz (Spanoqui había trabajado en las fortificaciones de Cádiz y quizá de ahi su traza similar), para municiones y almacenes, por la excesiva humedad y calor de la tierra, que pudre todo". Por lo que se refiere a Cartagena de Indias, en 1609 se decidió que el fuerte de la Punta del Judío se hiciera conforme a las trazas que Spanoqui había dado, y en 1610 escribía el gobernador lo difícil que habia sido sacar los cimientos, ya que «la planta era cuadrada y el sitio puntiagudo" ${ }^{9}$. Ejemplos ambos (con dos es suficiente, aunque algunos más se conocen) muy claros de lo necesario que era para un ingeniero el conocer el terreno en que se iba a edificar, necesidad que todos los tratadistas señalaron: Zanchi, Escalante, Rojas...

Las obras de Cádiz tuvieron ocupado a Spanoqui en diversas ocasiones, e incluso tuvo que residir alli por un tiempo, siendo suya la traza general de esas fortificaciones ${ }^{10}$. Trabajó también en las fortificaciones de Aragón, sobre todo en Zaragoza y en los valles del Pirineo, siendo suya la traza de la ciudadela de San Pedro, en Jaca, y el proyecto de fortificación de la Aljafería en Zaragoza, aparte de otras muchas intervenciones de menor importancia. Entre 1594 y 1598 estuvo encargado de las fortificaciones de Guipúzcoa, y ya en el reinado de Felipe III, siendo “Ingeniero Mayor de los Reinos de España» tuvo que volver a visitar esas fortificaciones, sobre todo Fuenterrabía y San Sebastián. Su actividad, en realidad abarcó todas las fortificaciones que se hacian o se reparaban en la península, y por ejemplo la costa de Galicia -sobre todo La Coruña- Santander o el reino de Portugal son otros territorios que fueron escenarios de su trabajo"1.

Aunque apenas se conocen, realizó Spanoqui informes detallados sobre las fortificaciones que tuvo que visitar a lo largo de su vida, y la zona en la que éstas se ubicaban. En ocasiones daba cuenta del número de vecinos, reconocia los valles por los que pasaba describiéndolos y dibujándolos, diseñaba la traza de los castillos y fortalezas proyectados, y en todo momento demostró unos conocimientos geográficos y científicos al dia. Sus viajes fueron, por lo tanto, constantes, y gracias a las sustancio-

9 D. Angulo IÑiguez: Bautista Antonelli. Las fortificaciones americanas del siglo XVI. Madrid, 1942, págs. 20 y 54. Y E. MARCO DORTA: Cartagena de Indias. La ciudad y sus monumentos. Sevilla, 1951, pág. 94.

10 V. Fernández Cano: Las defensas de Cádiz en la Edad Moderna. Sevilla, 1973.

11 Todas las noticias sobre Spanoqui, cuando no se cita referencia de archivo u otra fuente están sacadas de la inestimable Colección Aparici, que se conserva en la Biblioteca Central Militar de Madrid, tomos I, III, V, VI, VII y IX. 
sas "ayudas de costa" recibidas (eso sí, siempre con retraso) pudieron ser realizados. Siempre estuvo bien pagado, y más desde que en 1601 fuera nombrado Ingeniero Mayor, probablemente gracias a la gestión del duque de Lerma. Murió ganando 1.600 ducados al año, y el mismo año de 1606 en que parece que murió ${ }^{12}$, le fueron concedidos además 400 ducados de renta de por vida. Su trabajo como Ingeniero Mayor -fue nombrado tal el 15 de abril de 1601- llevaba aparejada la superintendencia de todas las fortificaciones, y le situaba en un nivel en el que sus únicos superiores eran el Consejo de Guerra y el Capitán General de Artillería. Sobre el dinero que cobraba, el Consejo mismo opinaba que todo lo que se le diera era poco, puesto que si faltase no vendria otra persona de su profesión "sin mas crecido sueldo, y otras mayores comodidades".

Spanoqui, que ya había pedido el título de Ingeniero Mayor en 1589 , fue además un hombre cuyo juicio fue tenido en cuenta en cosas tocantes a la guerra. En la Biblioteca Nacional de Madrid se conserva también el informe que dio al rey cuando se preparaba la Armada contra Inglaterra ${ }^{13}$. Solicitó participar y no le fue concedido, aunque sí a su hermano Mario, que murió en la empresa ${ }^{14}$. Consideraba en este informe que todo estaba a favor de España -razón, barcos, hombres, capitanes... - y aconsejaba sobre el número de barcos y sus clases, soldados, caballos, etc., que debían ir. Por otro lado, al pasar revista a los potenciales aliados del enemigo, y sobre todo a los lugares en los que era posible que el ejército español fuera atacado (Pirineos, Flandes, Milán...), deja ver su fe en las fortificaciones que en todos esos lugares salvaguardaban los intereses de la Monarquia española. Estaba expresando con ello una opinión generalizada en la época y que justificaba la necesidad de buenos ingenieros, como él mismo, por parte de las Monarquias europeas. Por otro lado, y

12 Aparici no encontró documentos sobre este ingeniero con posterioridad a esa fecha. En el Archivo de Protocolos de Madrid, 1857, hoja 484, hay una referencia de una carta de pago de Jerónimo de Soto, ingeniero, como testamentario de "Tiburcio Esparroqui", de 14 de enero de 1608. La noticia máx exacta sobre su muerte nos la da hasta el momento G. DELLA VALLE: Lettere sanesi..., Roma, 1786, tomo III, pág. 397. Afirma della Valle que murió el 4 de febrero de 1606, y que fue enterrado en Madrid, en la iglesia de los Clérigos Menores (habia nacido en Siena el 18-X-1541).

13 B.N.M. Ms. $n^{\circ}$ 979: Discorso al Re Catt, per l'Impressa d'ingliiterra. Del Cavalier fra Tiburtio Spannocchi. Se encuentra traducido en el Ms. $n^{\circ} 1750$ de la misma Biblioteca 6 hojas a partir del f. 418): Discurso del cavallero Spanoquio y exhortación para la empresa de Inglaterra Al Potentisimo Rey Philipe $2^{\circ}$. Según G. DEILA VALLE: Lettere Sanesi del padre maestro..., vol. III, Roma, 1786, este discurso "si legge in stampa", pero yo no to he encontrado impreso.

${ }^{14}$ Archivo General de Simancas (a partir de ahora A.G.S.)/Guerra Antigua (a partir de ahora, G.A), leg. 203, f. 44: se propone a ¿Tomás? Spanoqui, hermano de Tiburcio, para la Armada. Leg. 204, f. 161 y 167; parecer sobre este ingeniero y aceptación de sus servicios en la Armada. 
como hombre del Renacimiento que era, no olvidó hacer referencia a la Antigüedad como ejemplo para ser emulado por el rey actual: no sólo se debía anunciar la empresa a la reina de Inglaterra "como acostumbravan los Romanos", por medio de un "Araldo", sino que, en este caso, Felipe II iba a ser un nuevo Julio César porque, como él, iba a conquistar Inglaterra $y$, como él, en muy breve tiempo.

En algún momento de su vida tuvo relación con la práctica de la arquitectura, lo cual es un dato más a añadir a la larga serie de ingenieros que en algún momento actuaron como arquitectos o próximos a éstos. En 1582, a poco de llegar a España, fue encargado por Felipe II de hacer la planta y descripción de Aranjuez ${ }^{15}$, y en 1601 , después de haber sido nombrado Ingeniero Mayor de los Reinos de España, el duque de Lerma, queriendo “levantar una gran casa en Valladolid» llevó «al ingeniero Espanoqui para que haga la planta y traza de ella ${ }^{16}$, aunque al parecer ésta no llegó a hacerse, ya que el duque compró otras casas desechando la idea de hacer una nueva.

Sus funciones fueron diversas, y sus opiniones sobre arquitectura nos interesan tanto como su famoso escrito sobre el remedio de las inundaciones del Guadalquivir en Sevilla, al que luego nos referiremos, pero sin duda su título de ingeniero era el único compatible con la nobleza de su nacimiento. Fue además Caballero de la Orden de San Juan de Jerusalén, en la que habia que probar una nobleza de al menos cien años de antigüedad, aparte de no tener una profesión vil o mercantili" ${ }^{17}$. No podía ser más que ingeniero, pues todo lo referente a la guerra había sido siempre asunto de nobles y príncipes, y en España la traza de fortificaciones habia estado, tiempo atrás, en manos nobles como Perafán de Rivera, duque de Alcalá de los Gazules y marqués de Tarifa ${ }^{18}$. Cuando el arte de la guerra y sus

15 A.G.S., G.A., leg. 171, f. 147: en 1584, se dice que "se alla ocupado en hacer la planta y descricion de Aranjuez por orden de V.M...".

16 L. Cabrera de Cordova: Relaciones de las cosas sucedidas en la corte de España desde 1599 hasta 1614. Madrid, 1857, pág. 80. En la pág. 195 da otra noticia referente a este ingeniero, de 1 de noviembre de 1603: “El Condestable partió de aqui ayer mañana, el cual se ha detenido por no habérsele entregado antes sus despachos; lleva consigo a Espanoque y a otros ingenieros para reconocer las plazas de Fuenterrabia y San Sebastián y las demás de aquella costa y avisar de los reparos de que tienen necesidad, para mandarse proveerm. Véase también sobre la traza para la casa del duque de Lerma: L. Cervera Vera: El conjunto palacial de la Villa de Lerma. Valencia, 1969, pág. 60 y MARTi Y ALONSO: Estudios histórico-artisticos relativos principalmente a Valladolid, Valladolid, 1898, 1901, pág. 601.

17 A. Javierre Mur: Pruebas de ingreso en la orden de San Juan de Jerusalén. Catálogo de las series de caballeros, religiosos y sirvientes de armas existentes en el Archivo Histórico Nacional. Madrid, s.a.

${ }^{18}$ Sobre este tema: Colección Aparici, tomo V, págs. 43 a 46 y 72 a 80 . A.G.S., G.A., leg. 62, f. 85 y 86. También J.A. MaRAVALL: Estado moderno y mentalidad social, tomo I, 1972, pág. 524. 
nuevas técnicas llegue a no estar en manos de nobles, sino de profesionales formados en la ingeniería, éstos acabarán en algunos casos siendo ennoblecidos, cosa de la que Spanoqui será testigo.

Tan necesaria era la labor de este ingeniero en la península, que en 1605 se le negará el permiso de ir a besar los pies de Pablo $V$, pariente y paisano suyo. Sirvió, según él mismo afirma, cuarenta años a la Monarquía española y entre los méritos en su haber que se alegaban en 1600 , estaba el haber formado -quizá en parte gracias a su labor en la Academia de Matemáticas fundada por Felipe II- a Cristóbal de Rojas, Leonardo Turriano, Gerónimo de Soto, Próspero Casola, Gaspar Ruiz, etc., aunque ninguno de ellos fue considerado lo suficientemente bueno por el Consejo como para sustituir a Spanoqui a su muerte.

Las trazas que se conservan de Spanoqui son sólo una parte de toda su producción. Sabemos, por ejemplo, que el rey le encargó, una vez nombrado Ingeniero Mayor, poner "en libros todas las trazas que hay y adelante hubiere de cosas de fortificación y sacar las copias que fuere necesario" ${ }^{19}$. Quizá sean esos los libros que según Maggiorotti acabaron con el tiempo en una torre del palacio del Retiro, dispersándose durante la Guerra de Sucesión. Las trazas e imágenes con que ilustró sus informes son de una gran belleza en la mayor parte de los casos, a pesar de no ser la fortificación el campo idóneo para que un ingeniero demostrara sus habilidades como pintor, al haber un protagonismo absoluto de cuestiones técnicas. A pesar de ello, y como decimos, algunos dibujos de Spanoqui muestran su excelente formación como pintor, habiendo aprendido los principios de ese arte en su juventud con Riccio, pintor sienés ${ }^{20}$.

De las trazas que de Spanoqui se conocen, hay varios temas que en este pequeño esbozo de su trayectoria profesional deben ser destacados. Como casi todos los ingenieros, su labor estuvo ligada a problemas urbanos en multitud de ocasiones.

De 1595 son, por ejemplo, dos imágenes de la villa de Pontevedra, de la que afirma que es alugar de muy buenos edificios assi Templos como de Cassas Plaças fuentes y jardines", aunque esté muy mal amurallada. En el "retrato" -así lo llama- que hace desde un punto de vista más próximo de esta villa (con un perímetro urbano fortificado y un arrabal importante) son los edificios religiosos los que utiliza como puntos de refe-

19 Colección Aparici, tomo VI. Según un documento de Simancas, con la antigua clasificación de "Mar y Tierra", leg. 597, año 1602. Véase la nota 4. Spanoqui, como grandes recopilaciones, haria por un lado la descripción que afirma estar haciendo similar a la de Sicilia, y por otro, la que le demandaba pasar a libros el monarca después de su nombramiento.

20 G. Della Valle, op. cit., págs. 395-396. 
rencia; Santa María la Grande, Monasterio de Santo Domingo, de San Francisco... en una sintesis figurativa que consagra una vez más el dominio de la iglesia sobre las estructuras urbanas en esta época.

En el parecer que dio en 1604 sobre la forma de acabar con las inundaciones del Guadalquivir en Sevilla, aborda el tema urbano desde otro punto de vista que no se refiere exclusivamente a la fortificación. Le fue necesario para su trabajo "sacar una puntual descriciō" de la ciudad, y afirma que a la relación acompaña una traza, que no aparece en el impreso. Estudia las causas de la catástrofe y apunta los remedios necesarios, que tendrá que poner en ejecución "el Maestro mayor luan de Oviedo". Afirma que los puentes de los rios en ciudades suelen "causar mayores inundaciones, y por solamente esta causa no se ã hecho en Triana puente de fabrica", y se muestra contrario a desviar por completo el curso del río, "que sin esta cōtrataciō perderiase totalmente su grandeça». Según dice hay que reparar las murallas "pero con unos prevenidos remedios de puertas, husillos y manantiales", evitando que se construyan casas pegadas a la muralla, pues provocan "licencias irreparables", y han sido causa en la última avenida de que se perdieran "las muchas mercaderias que se hallaron en la Aduana». Todos los problemas de una nueva muralla: su trazado, utilidad, financiación, control, etc. son abordados en este interesante escrito, asi como lo referente a la Aduana, a ordenanzas generales sobre construcción en la ciudad, a los costes, e incluso, a problemas de basuras. No es el caso de analizarlo aquí pues merece un estudio más amplio en relación con los problemas urbanos en la España de la época, así que nos limitamos a señalar su importancia ${ }^{21}$.

En varias ocasiones, y en relación también con el tema de la ciudad, Spanoqui abordó el problema de las ciudadelas, ampliamente tratado en los libros de arquitectura militar del siglo XVI. En Pamplona (Fig. 3) debió seguir la traza dada por el Fratín ${ }^{22}$, pero en Jaca se siguió su propia traza. Ambas ciudadelas siguen el modelo pentagonal, modelo casi universal para esta tipologia en la segunda mitad del siglo xvi; en otros lugares de Europa, en los que la ciudadela fue también instrumento de control de un territorio, como es el caso de Amberes, de Parma, de Piacenza o de Turín, se utilizó el mismo tipo de fortaleza pentagonal ${ }^{23}$. La ciudadela de Jaca

\footnotetext{
${ }^{21}$ Parecer que dio el Comendador Tiburcio Spanoqui Cavallero del Abito de San Juan, ingeniero mayor de su Magestad y Gentilhombre de su Casa. A la muy noble y muy leal Ciudad de Sevilla, sobre los Reparos que convienen para la inundación del Rio Guadalquivir. Impreso en Sevilla en Casa de Francisco Pérez. Año de 1604.

22 A.G.S., G.A., leg. 461 , f. 115.

${ }^{23}$ Sobre el tema de la ciudadela, véase, aparte de todos los tratadistas que tratan el tema, y la bibliografía específica sobre cada una de esas ciudadelas, un planteamiento general en A. Guidoni y Marino: Storia dell'Urbanistica, /l Cinquecento. Roma, Bari, 1982.
} 
(Fig. 4), o castillo de San Pedro, trazada por Spanoqui, es un eslabón más en la continuidad de esa tipologia ${ }^{24}$, que repetirá en casos distintos no sólo la idea general, sino incluso detalles como los de las puertas. Así por ejemplo, sabemos que en marzo de 1613 se estaba haciendo la portada del Castillo de Jaca, con traza igual a la de Pamplona ${ }^{25}$. Además de los ejemplos citados, Spanoqui también propondrá la construcción en Cádiz de otra ciudadela, que no se llegó a realizar, pero cuya conveniencia se discutió durante mucho tiempo ${ }^{26}$.

En otro momento volverá a abordar el problema: es el caso de la Aljafería de Zaragoza (Fig. 1), en la que hubo que adaptar el antiguo edificio, que era la sede de la Inquisición. Ya en 1592 Spanoqui pasó por Zaragoza con encargo de ver las posibilidades de fortificar ese lugar, advirtiéndosele que lo hiciera "con disimulación" 27 , pues los recientes sucesos así lo aconsejaban. La fortificación de la Aljafería fue una de sus obras más famosas, e incluso algún viajero dejó constancia de ello: Camilo Borghese vio este edificio, y escribió lo siguiente: “... y habiendo visto la Aljaferia, palacio real de la ciudad, asi llamado por el rey que lo construyó, que tenia este nombre, que ahora está convertido en fortaleza de su majestad por el señor caballero Tiburzio Spannocchia, gentilhombre sienés, por la sublevación que ocurrió dos años antes por Antonio Pérez" ${ }^{28}$.

Hubo muchas consultas antes de decidirse a fortificar una zona $u$ otra de la ciudad, obligada a aceptar una ciudadela ante las posibilidades de sublevación. Se propuso, por ejemplo, hacer el castillo cerca de la Aljaferia, en el lugar que en el plano se señala con el número 28 , pues así estaria situado "en parte que mate y espante", y además no habría que derribar casas. Otras posibilidades obligarian en cambio a derribar casas y monasterios, e incluso una de las que se barajó, aparte del derribo de casas principales hubiera llevado aparejado el derribo de la iglesia de Nuestra Señora del Pilar ${ }^{29}$; ante todo esto parece lógica la decisión tomada de convertir en ciudadela la "cassa del sancto officio", que en el plano aparece con el número 27 (Fig. 5).

${ }^{24}$ Sobre la construcción de esta ciudadela: R. DEL ARCO: "La ciudadela de Jaca». Archivo Español de Arte, 1945, pág. 277-291.

25 A.G.S., G.A., leg. 785 , s.f.

26 V. Fernandez Cano, op. cit, passim.

27 A.G.S., G.A., leg. 349, f. 183.

${ }^{28}$ Camilo BORGHESE: "Diario de la Relación del viaje de Monseñor... auditor de la Rev. Cámara de Roma en España enviado a la corte como nuncio extraordinario del Papa Clemente VIII el año 1594 al rey Felipe II». En J. Garcia MERCADAL: Viajes de extranjeros por España y Portugal, vol. I, Madrid, 1952, pág. 1469.

29 A.G.S., G.A., leg. 349, f. 182. 
Remitidas las trazas al conde de Chinchón (personaje clave en lo referente a la arquitectura en el reinado de Felipe II) el 2 de julio de 1593, su forma hubo de adaptarse a lo preexistente, construyéndose la fortaleza de argamasa y ladrilio, con cadenas de sillares en las esquinas. Los huecos de las ventanas se enmarcan dentro del gusto manierista y son las dos puertas, sobre todo la principal, las que concentran la decoración y la potencia expresiva del edificio. Ambas son de piedra, de grandes sillares almohadillados perfectamente visibles desde la lejanía. La puerta principal resultaba además ennoblecida por la (a modo de) balconada que la coronaba, y enriquecida en su mensaje de poder con el escudo: la desnudez de los muros acentuará todavia más los valores estéticos y expresivos de ese punto de atracción que era la puerta. Las puertas en las fortificaciones fueron a la vez punto débil y frontera entre el exterior y el interior, y sólo en ellas eran posibles los experimentalismos (órdenes, decoración...) siempre que se respetara el ineludible carácter amenazador. Fueron las puertas de las fortalezas un episodio arquitectónico en el que se patentizó la vinculación entre arquitectura e ingenieria, aunque otros aspectos más complejos deben ser analizados en el mismo sentido.

Spanoqui es uno de los ingenieros más citado en textos ajenos a la materia de fortificación, así que, aparte de los textos ya vistos, podemos recordar aqui también el de Mantuano, que escribe que Fuenterrabia (Fig. 2) "solo tiene un baluarte labrado a lo moderno. Obra començada de Vespasiano Gonzaga, y acabada del Cavallero Tribulcio... cuya cortina tiene por la una parte trezientos y veynte y dos pies geométricos, y a la vanda de la puerta, quinientos y veynte y uno, començado de diferente forma de Vespasiano Gonzaga, aviendolo traçado, y formado de tierra mucho mayor, y de angulo mas agudo" ${ }^{30}$; como comprobamos, la evolución en el arte de la fortificación, queda también reflejada en el texto.

Aparte de las trazas que Spanoqui dio a lo largo de su vida, a algunas de las cuales hemos hecho referencia, hizo también «modelos de bulto" o "modelos de madera" de algunas fortificaciones; propuso por ejemplo hacer uno de Gibraltar ${ }^{31}$, hizo uno de Fuenterrabía en 1581, aunque por la dificultad de trasladarlo, proponía ir él mismo a la corte con las medidas para hacerlo mejor, habiendo además en la corte «entalladores y pintores más abiles" para ello ${ }^{32}$. Hizo también en 1595 un modelo de bulto del castillo de "Venasque» en el Pirineo, en el que se podían ver los problemas

30 Pedro Mantuano: Casamientos de España y Francia, y viaje del Duque de Lerma llevando la Reyna christianissima Doña Ana de Austria al passo de Beobia, y trayendo la princesa de Asturias nuestra señora. Madrid, Tomas lunti, 1618, págs. 219-221.

${ }^{31}$ Colección Aparici, tomo III, pág. 36.

32 A.G.S., G.A., leg. 110, f. 22. 
del paso en esa zona ${ }^{33}$. Probablemente muchos más fueron trazados por él, pasando a engrosar la enorme información que Felipe II quiso tener de todas sus tierras ${ }^{34}$.

Las funciones y responsabilidades de los ingenieros abarcaban muchos más campos que el propiamente de la fortificación, con ser éste el principal, tal como podemos comprobar con este rápido esbozo de la carrera de Spanoqui en España. Antes de acabar debemos recordar todavía algo a lo que antes ya se ha hecho alusión, y es lo siguiente: todo ingeniero podía ser contratado como arquitecto (a pesar de las prohibiciones de que quien trabajara en las fortificaciones trabajara también en obras particulares en las ciudades), pero no sucedía lo mismo a la inversa, pues los arquitectos militares 0 ingenieros de fortificación debian tener unos conocimientos y una experiencia que superaba a la formación que un arquitecto recibia. La progresiva especialización de los saberes y de las artes se dio también en esta profesión, aunque las crisis económicas y la falta de profesionales contribuyeron durante mucho tiempo todavía a que los límites entre ambas profesiones, arquitecto e ingeniero, quedaran difusos. De todas formas, hay una cuestión a reflexionar, y es que los grandes ingenieros nunca fueron confundidos con maestros de obra, nunca tuvieron que defender un estatus que nadie les negó; enlazaron la idea del noble guerrero con la de los profesionales especializados (que con el tiempo fue por completo independiente de la nobleza de su sangre), y fueron protagonistas de una praxis arquitectónica acosada por las necesidades de las modernas Monarquías. Tiburcio Spanoqui puede ser un ejemplo de todo ello.

33 A.G.S., G.A., leg. 461 , f. 81.

${ }^{34}$ R.L. Kagan: “Felipe Il y los geografos". En Ciudades de/ Siglo de Oro. Las Vistas Españolas de Anton Van den Wygaerde, Madrid, 1986. 


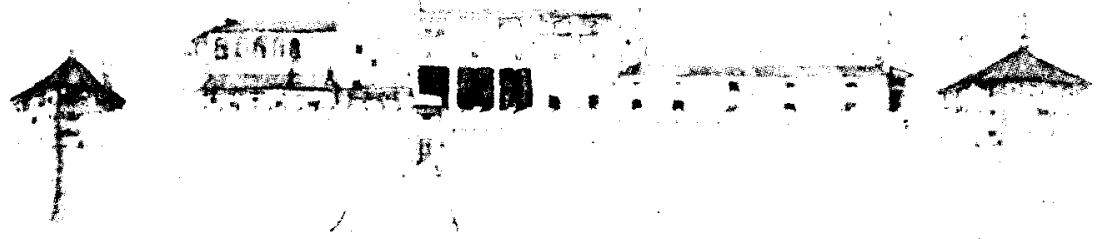

Fig. 1. Spanoqui: Aljafería de Zaragoza. Julio, 1593 (A.G.S., M.P. y D. V-85).

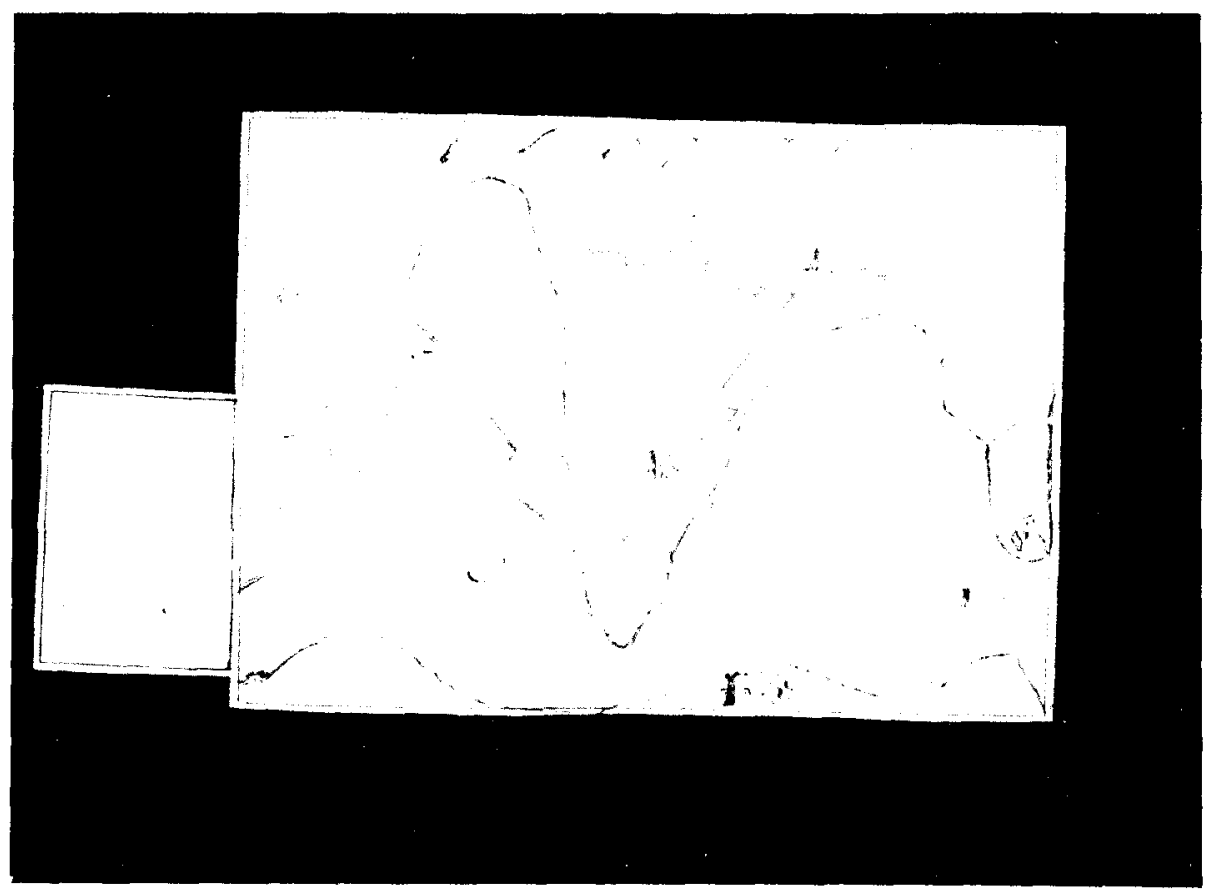

Fig. 2. Fuenterrabia (s.f.) (1667) (A.G.S., M.P. y D. VIII-89). 


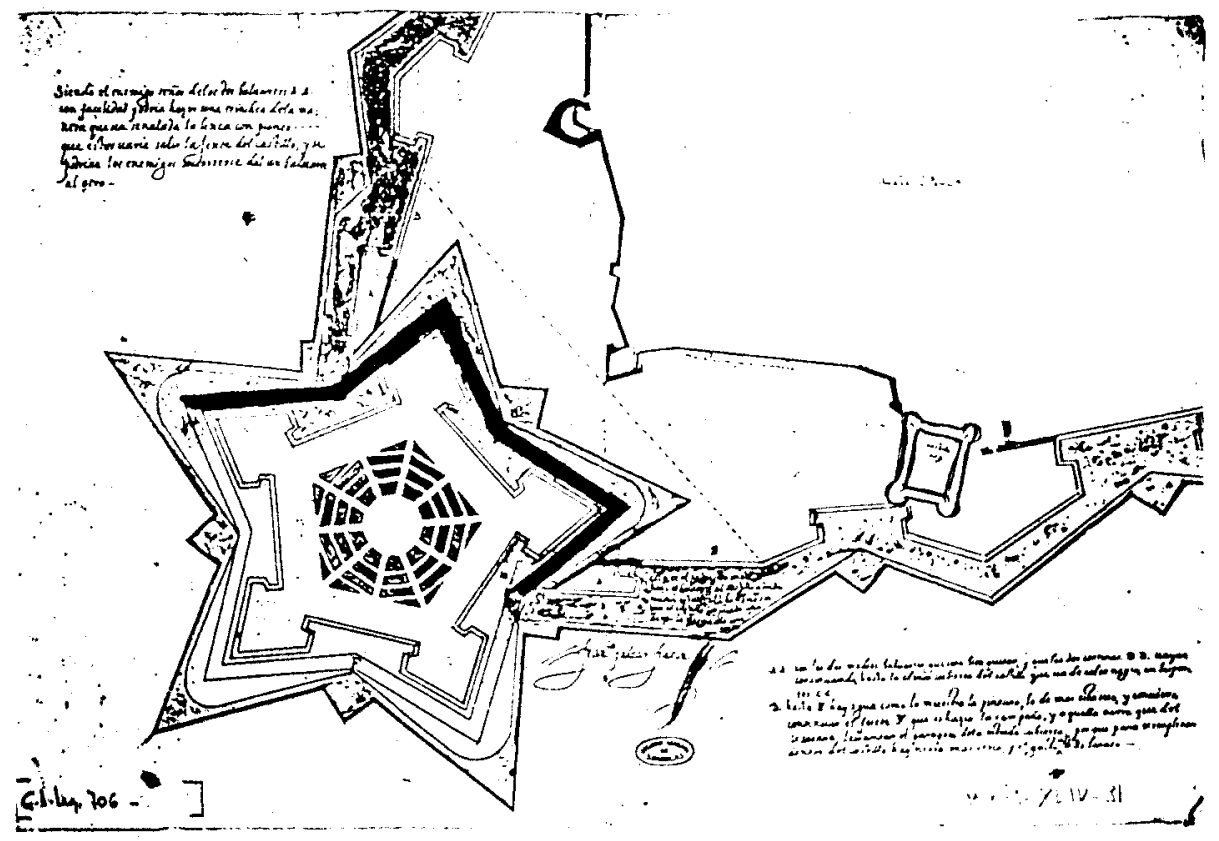

Fig. 3. Ciudadela de Pamplona. Francisco Palear Fratin. Septiembre, 1608 (A.G.S., M.P. y D. XLIV-31).

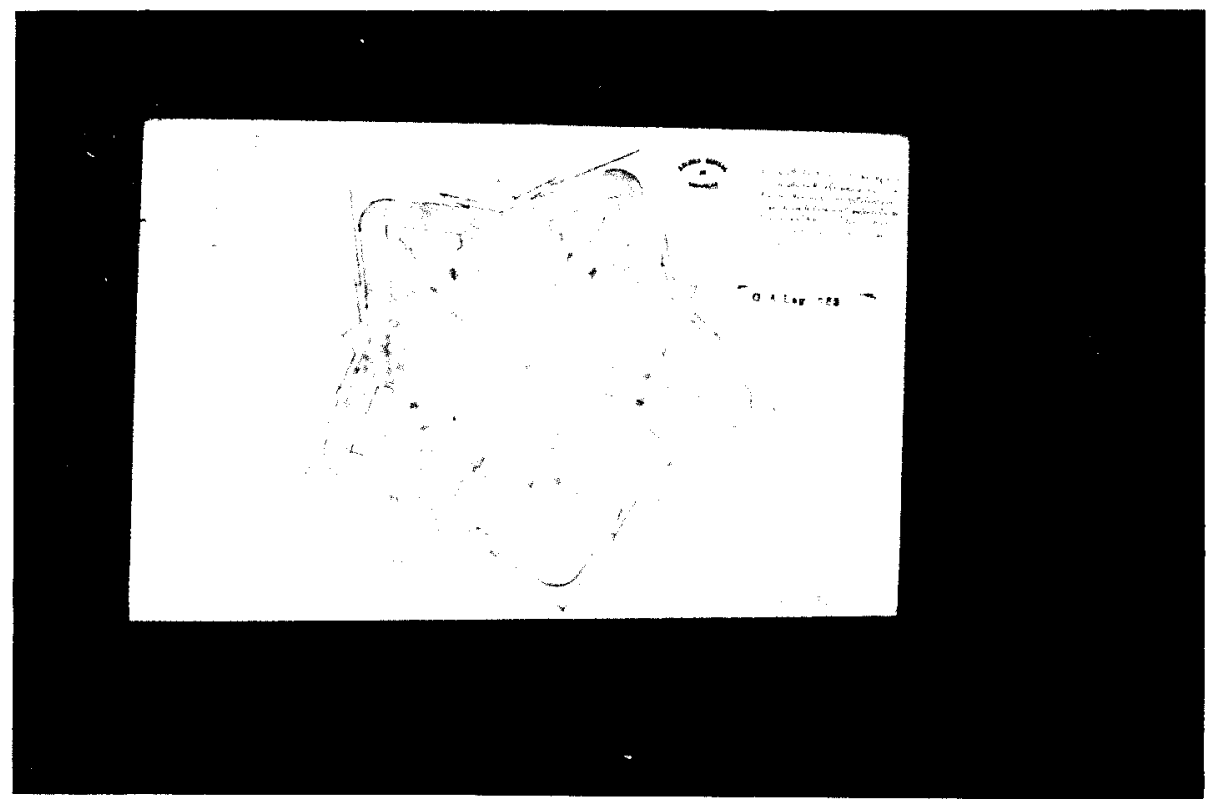

Fig. 4. Spanoqui: Castillo de San Pedro, comenzado en Jaca. Mayo, 1592 (A.G.S., M.P. y D. XXXVIII-92). 


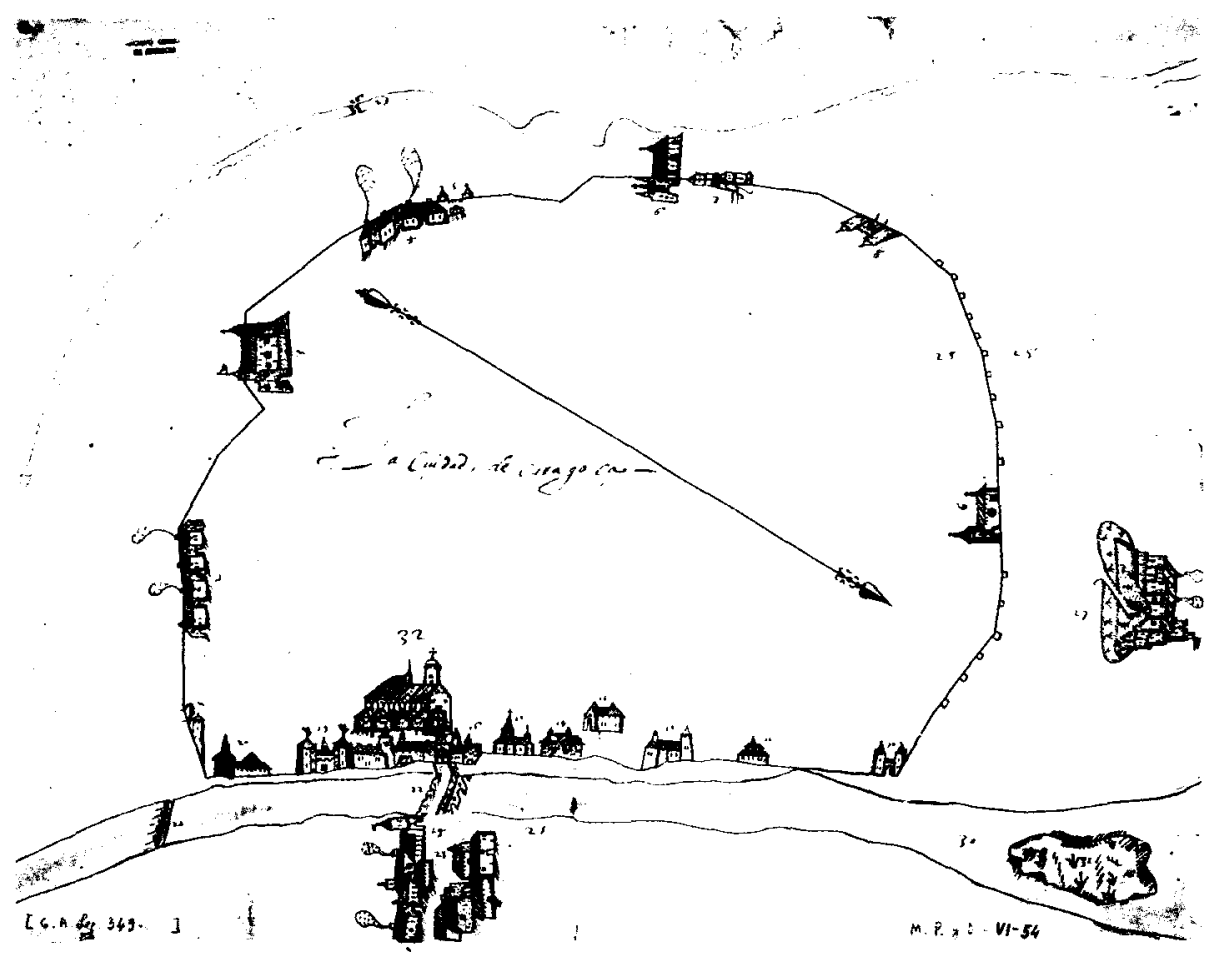

Fig. 5. Planta de la ciudad de Zaragoza, 1592 (A.G.S., M.P. y D. VI-54). 